\title{
Flies in amber: Capturing brand equity-effects in South African rosé wines
}

\author{
D. Priilaid*, J. Barendse, C. Kato-Kalule and A. Mubangizi \\ School of Management Studies, University of Cape Town, \\ Private Bag, Rondebosch 7701, Republic of South Africa \\ David.Priilaid@uct.ac.za
}

\begin{abstract}
With previous wine marketing studies confirming the effect of extrinsic cues such as price, area-of-origin, and expert ratings on sighted appreciation, we report on a tasting room experiment aimed to determine the prevalence and impact of wine brands across user categories of education, gender, expertise and age. Here 83 subjects assessed six different entry-level rosé wine brands, first blind and then sighted. During the sighted round the only cue information made available was the brand of each wine. A database of 498 paired blind and sighted wine assessments was thus constituted. The subsequent statistical interrogation of those factors impacting on a wine's sighted appreciation reveals (1) the extent to which certain wines present with significant brand effects, while others do not, and (2) how different brand assemblages accrue across certain user profiles. While two men's brands were clearly identified, females, in particular, appeared to be more influenced by certain brands, as did those with higher levels of education. The methods and findings of this paper demonstrate how one might more cost effectively test for and deploy particular brands within particular user categories.
\end{abstract}

*To whom all correspondence should be addressed.

\section{Introduction}

A growing body of contemporary wine marketing literature lends focus to the role of extrinsic cues, and the extent to which these mediate the objective assessment of a wine's merit. For customers of wine such cues are important. Studies have revealed the extent to which consumers deploy such cues as proxies of quality, particularly when direct sampling is not possible; as is the case with wine (Halstead, 2002; Spawton, 1991; Mueller, Osidacz, Francis \& Lockshin, 2010.)

A number of placebo-type extrinsic wine cues have been studied for this effect, including: price (Plassmann et al., 2008), expert ratings (Siegrist \& Cousin, 2009), and brand (Priilaid \& Van Rensburg, 2010). Although research into wine brands has shown promise, no work has served to examine the extent to which brand-cues configure across user-profile-bands such as age, gender and education. It is this hitherto unexplored line of wine-brand-analysis that this piece of research seeks to investigate. Within a profile of youthful consumers, in the sighted assessment of wines: are men more affected by particular brands than women? Which brands might these be? What of the effect of education? Are those with some tertiary education more brand conscious than those without? It is questions of this sort that this study seeks to answer.

To proceed we observe that wine evaluations can be conducted either blind or sighted. Embedded within the scores of sighted wine assessments is the aggregate bias of any prevalent extrinsic cues. Blind scores are void of such bias. By statistically controlling for the intrinsic merit of each wine, in sighted assessments the incidence and relative influence of an extrinsic brand-cue can thus be observed, as might a fly in a petrified shard of amber, or the passage of a ghost through a machine.

To proceed, a two-round tasting room experiment was conducted in which 83 subjects assessed six rosé wines: first blind and then sighted. A different sequence of tasting was employed in each round, with the rosé wine 'style' made known to participants in each round of tasting, and the identity of each wine-brand the only additional cueinformation being made available in the second (i.e. sighted) round of tasting. Each of the six rosé wines constituted an entry-level brand, the unrevealed prices of which are immaterial to the study but which did not exceed R35.

Merging the round one and two assessment-scores of each participant, a database of 498 paired blind and sighted wine assessments was then compiled and analysed to compute any brand effects as these presented across a range of demographic user-profiles. As with similar studies of this nature, we contend that in the sighted assessment of wine, prevailing cues (in this instance brands) are likely to subvert the relative contribution of a wine's intrinsic merit. In the instance of this experiment, we seek to know which brands these might be, in which user-segmentations they most typically accrue, and the extent of their coercive influence. 
Hereafter, in Section Two, follows a review of the relevant literature. A description of the experimental design and the subsequent dataset is the presented in Section Three. Subsequently, Section Four outlines the statistical findings, with a concluding discussion following in Section Five.

\section{Literature review}

Belief in the supposed efficacy of a product is pivotal to our understanding of a placebo effect, which, according to Moerman and Jonas (2002: 472) is the response to the meaning 'elicited after the use of inert or sham treatment.' Thus, as these authors assert, while as 'inactive substances' (Borsook \& Becerra, 2005: 394), placebos cannot do anything in and of themselves, the meanings attached to them can. These meanings are symbolic - and serve as enablers of belief. Outside of medicine they are consumed daily by way of a multitude of social-cultural constructs, including, kisses, glares, product prices, and brands; all extrinsic cues in one form or other.

The neurological dynamics that govern the placebo-effect have drawn increasing research interest, and work by Montague (2006) and Plassmann et al., (2008) argues that extrinsic cues are deployed by our brains as non-conscious information filters to make rapid and optimal sense of fluid information-rich environments. Montague (2006) suggests that this is a prehistoric phenomenon, in which, for example, the sound of a snapping twig was employed 'symbolically' as an extrinsic cue to connote the danger of an approaching predator. Today snapping twig-like cues are unwittingly invoked in the supermarket jungles to assist in the selection of products, like wine, when their intrinsic merit cannot be readily attested (Thrane, 2004). In the realm of wine marketing research, a number of placebo-type cues have borne scrutiny, including price (Plassmann et al., 2008; Almenberg \& Dreber, 2011), area-of-origin and terroir (Priilaid, 2006 \& 2007), and expert ratings (Siegrist \& Cousin, 2009), inter-alia.

By contrast to those cues cited above, the brand cue has attracted little interest in the wine-placebo literature. This is perhaps surprising, since brands form one of the key drivers of market expectations, and are consumed as concepts (Ariely \& Norton, 2009). As such they are laden with expectation (Allison \& Uhl, 1964), and symbolic meaning. In the only wine-brand as placebo piece of research currently identified, Priilaid and van Rensburg (2010) differentiated clearly between functional wine brands which present only with consistent levels of blind-based quality, and symbolic brands, which present with statistically consistent differences between measures of intrinsic and extrinsic quality. The genealogy of this value-added definition runs deep, aligning clearly with the base-line theories of Kamakura and Russell (1993), Keller (1993) and Erdem and Swait (1998), inter-alia. Employing 8225 paired (sighted and blind) tastings sampled by wine professionals over eight years, the 2010 study identified a number of functional and symbolic brand effects and proceeded to catalogue their effect-sizes and map their dispersion. By so doing, these authors argued, wine brand managers could now identify which of their charges were registering as symbolic placebo-type brands, and strategise accordingly.
While all this was true, the subjects employed in the 2010 paper were all wine-tasting professionals, not the general wine-drinking public itself. This created certain practical difficulties. In the first instance, ordinary drinkers, although clearly influenced by the ratings of professional tasters (Priilaid et al., 2009), are the more direct custodians of the brands on offer. Testing non-professionals is, in this light, a more pragmatic route to brand identification. In the second instance, existing professional tasting files might not always carry a record of those particular candidate brands that require testing now; such omissions negating the possibility of directly testing for such brands. In the third, while the professional record runs deep - in the 2010 paper to over eight years of tasting - it is usually the output of between only one and four tasters from a particular sub-section of the market. Inferences about brand preferences within other segmentations can thus not be made.

Proceeding from an appreciation of the above, it should be clear that the direct testing of ordinary wine consumers provides a useful alternative to brand testing from a professional record as per Priilaid and Van Rensburg (2010). This being so, we need also to consider how brand-cue assemblages configure across the broader population; and how these might differ across user-transects such as age, gender and experience. Accordingly, certain key objectives present themselves for this study.

Firstly, and at a meta-level of analysis: controlling for intrinsic merit, which if any wines present themselves as placebo-type brands? Given a range of wines tested for intrinsic and extrinsic merit we, would anticipate that some present as statistically significant, while others do not. Secondly, we would expect brand assemblages to differ across user profiles segmented by way of age, education, and the like. Aligned with the comparative work on wineprice-cues by Almenberg and Dreber (2011) and Priilaid et al., (2013) we would, for example, expect a distinctive difference between the cue-effects stemming from men and women. Comparative tests run on certain sub-segmentations would serve to establish whether this is so.

\section{Data description and model construction}

\section{Data description}

This study sought to examine how the equity of entry-level type wine brands influences the sighted quality assessments of young South Africans between 18 and 30 years old. Due to timing and cost constraints, the Western Cape was chosen as the sample area, with subjects emanating from Cape Town and Stellenbosch.

In a one group pre-experimental design-format (Malhotra, 2010: 158) similar to that employed by Priilaid et al., in both 2009 and 2013, 83 subjects (45 males; 38 females) participated in a two-round blind-to-sighted wine tasting. Round one was a seven-wine blind tasting in which subjects were informed only of the wine-style to be sampled: in this case rosé. Round two was the 'sighted' tasting. Here one of the seven wines was removed from the line-up, the remaining six of which were shown to the subjects, although assessed in a different sequence. The six wine brands 
employed were: Robertson's Winery, St Claire, Es La Vida, $4^{\text {th }}$ Street, Cellar Cask and Four Cousins.

Before commencement of tasting, subjects were requested, by way of a questionnaire, to provide information on their gender, age, education, glasses of wine consumed per week, and relative knowledge of wine (ranging from 'novice' to 'intermediate' to 'expert'). The twenty-point (or) 'five star' system of wine tasting was employed throughout. This system of scoring is widely employed in the South African wine industry and has featured in previous studies of this nature (see inter-alia Priilaid et al., 2009). A score of 18 or more attracts the superlative five stars. Scores between 16 and 17 are awarded four stars, scores of 15: three stars. A 14 point score gets two stars, and one star equates to 13 out of 20.

Merging figures drawn from the 83 self-administered questionnaires of the six wines assessed in the two blind and sighted rounds, we constructed a dataset of 498 paired wine tastings.

Descriptive statistics pertaining to the dataset appear in Table 1 below. Controlling for intrinsic merit, statistical tests were then conducted to determine the size of any brand cue as it presented within the modelling of sighted scores. With other extrinsic cues such as price and vintage all undisclosed, no additional methodological controls were required.

\section{Model construction}

The Spearman correlation coefficient between blind and sighted wine assessment-scores is calculated to be 0.515 , a figure significant at the 0.01 level (2-tailed) that, while medium-positive in strength, suggests that over and above the influence of intrinsic merit, certain brands might also be influencing the sighted tastings of round two. To test for this, a number of descriptive variables are codified along with the six brands as dummy variables, and presented as non-linear categorical variables. These are: 'gender', 'age', 'education', 'drinks per week', 'years drinking wine', and 'knowledge of the wine industry'. Age is split into two categories: the very young ' $18-21$ ' $(\mathrm{n}=47)$, and the relatively older '22-30' $(\mathrm{n}=36)$. The variable 'education' is divided into two categories: 'secondary education' (that being any high-school qualification) $(\mathrm{n}=46)$, and 'tertiary education' $(\mathrm{n}=37)$ (that being a post-matric qualification: a technicon diploma or a university degree of some sort). Three categorical variables cover 'drinks per week': 'one to three' $(n=65)$, 'four to six' $(n=12)$ and 'seven or more' $(n=6)$, and two categorical variables span 'years drinking wine', namely: 'one to four' $(n=69)$, and 'five or more' $(n=14)$. Finally we divided the 'knowledge of the wine industry' variable into two categories: 'novice' $(\mathrm{n}=56)$, and 'intermediate' $(\mathrm{n}=27)$. (Although subjects were given an 'expert' option on the questionnaire, we found that they did not feel confident enough to call themselves wine 'experts'.)

With the appropriate controls in place, a series of stepwise regressions was run against the sighted scores in order to identify the presence of any placebo-type brands. In addition to a (1) meta-model of general usage, we also sought to investigate how certain brands configured within certain sub-general user-categories. Models were thus also developed along the following lines: education ((2) secondary versus (3) tertiary), gender ((4) male versus (5) female), wine-experience ((6) novice versus (7) intermediate), and age ((8) between 18 and 21 years versus (9) 22 years or older).

We avoided the dummy trap by specifying certain dummified points of reference, namely: 'Brand': Robertson Winery, 'Age': 22 or older, 'Gender': female, 'Education': tertiary, 'Drinks per Week': more than six, 'Years Drinking': more than four, and 'Knowledge of Industry': intermediate. Additionally, since six paired blind and sighted observations are derived from each of the 83 subjects, observations cannot be deemed independent. Thus we also establish subject-level dummies to control for any overt individual bias across each set of model respondents. Accordingly: respondent 1 is employed as the comparator for the general, secondary education, male, novice and 18 to 21 year models, while respondent 58 is employed in the tertiary education, female, intermediate and 22 years or older models. Thus, for the models that follow, all variable coefficients should be considered specific to these comparators, which, in themselves, represent as the constant term derived in each model-equation that follows.

Table 1: Descriptive statistics. Note: of the 83 subjects: males=45, females=38

\begin{tabular}{|c|c|c|c|c|c|}
\hline & $\begin{array}{c}\text { Sighted } \\
\text { tasting }\end{array}$ & $\begin{array}{l}\text { Blind } \\
\text { tasting }\end{array}$ & $\begin{array}{l}\text { Years of } \\
\text { drinking }\end{array}$ & $\begin{array}{c}\text { Drinks } \\
\text { per week }\end{array}$ & $\begin{array}{l}\text { Age of } \\
\text { subject }\end{array}$ \\
\hline Minimum & 0 & 0 & 1 & 1 & 18 \\
\hline Maximum & 5 & 5 & 11 & 7 & 30 \\
\hline Median & 2,5 & 2,5 & 2,5 & 2 & 20 \\
\hline Mode & 3 & 3 & 2,5 & 2 & 20 \\
\hline Mean average & 2,51 & 2,35 & 3,36 & 2,80 & 21,40 \\
\hline Standard Deviation & 1,06 & 1,01 & 1,99 & 1,58 & 2,68 \\
\hline Range & 5 & 5 & 10 & 6 & 12 \\
\hline Kurtosis & $-0,25$ & $-0,24$ & 4,04 & 1,32 & 1,19 \\
\hline Skewness & $-0,12$ & $-0,15$ & 2,21 & 1,68 & 1,45 \\
\hline $\mathbf{n}$ & 498 & 498 & 83 & 83 & 83 \\
\hline
\end{tabular}


Table 2: Estimated step-wise regressions explaining sighted wine assessments. As per the overall $\mathrm{P}$ and $F$ scores observe that all models are statistically significant. Model variables appear in the sequence: constant, blind rating, brand, subject control, behavioural control. All variables are statistically significant at the 5\% level; their coefficients presented by order of the absolute value of their associated $t$-statistic which appears alongside in parenthesis.

1. Meta-model: Sighted: $\operatorname{Adj} R^{2}: 46.43 \%, F: 19.72(p=0.0000, n=483$.

Constant: $1.77(15.57)$

Blind Rating: 0.37 (9.22)

Brand: Es La Vida: -0.43 (-4.35), Cellar Cask: -0.37 (-3.70), Four Cousins: 0.25 (2.53)

Subject control: subj. 4: 1.59 (4.96), subj. 27: -1.56 (-4.85), subj. 29: -1.15 (-3.59), subj. 26: -1.16 (-3.57), subj. $56: 0.98$ (3.03), subj. 59 : 0.97 (2.95), subj. 51: 0.93 (2.91), subj. 31: 0.92 (2.87), subj. 69: 0.90 (2.77), subj. $48:-0.86(-2.68)$, subj. 18: -0.85 (-2.65), subj. 33: -0.84 (-2.62), subj. $20:-0.80$ (-2.48), subj. 82: -0.69 (-2.16), subj. 35: $-0.70(-2.16)$, subj. 68: $-0.70(-2.16)$, subj. 36: $0.69(2.15)$, subj. 6: $0.66(2.04)$, subj. 42: $-0.64(-2.00)$.

2. Secondary Education model: Sighted: $\operatorname{Adj} R^{2}: 36.23 \%, F: 16.57(p=0.0000), n=276$.

Constant: $1.40(9.58)$.

Blind Rating: 0.43 (7.77).

Brand: Four Cousins: 0.33 (2.33).

Subject control: subj. 27: -1.44 (-4.06), subj. 29: -1.05 (-2.97), subj. 31: 0.99 (2.82), subj. 26: -1.01 (-2.81), subj. 51: 0.97 (2.77), subj. 18: -0.75 (-2.13), subj 33: $-0.72(-2.05)$, subj. 20: $-0.70(-2.00)$.

3. Tertiary Education model: Sighted: $\operatorname{Adj} R^{2}: 52.66 \%, F: 19.91(p=0.0000), n=222$.

Constant: $1.66(11.69)$

Blind Rating: 0.37 (6.88).

Brand: Four Cousins: 0.52 (3.77), Brand: Es La Vida: -0.34 (-2.53), Brand: St Claire: 0.34 (2.44).

Subject control: subj. 4: 1.51 (5.04), subj. 48: -0.94 (-3.11), subj. 56: 0.89 (2.93), subj. 59: 0.88 (2.81), subj. 69: 0.81 (2.66), subj. 35: -0.77 (-2.56), subj. 68: $-0.77(-2.56)$, subj. 67: $-0.68(-2.26)$, subj. 36: $0.61(2.04)$.

4. Male model: Sighted: Adj $R^{2}: 61.48 \%, F: 26.87(p=0.0000), n=228$.

Constant: $1.78(9.65)$.

Blind Rating: 0.40 (7.87).

Brand: St Claire: 0.51 (4.50), Brand: Four Cousins: 0.50 (4.42).

Subject control: subj. 27: -1.47 (-5.59), subj. 4: 1.22 (4.12), subj. 56: 1 (3.75), subj. 59: 0.96 (3.52), subj. 69: 0.91 (3.43),

subj. 48 : -0.77 (-2.92), subj. 6: 0.68 (2.58), subj. 35: -0.60 (-2.28), subj. 60: 0.56 (2.13), subj. 14: 0.58 (-2.25).

Behavioural control: Years Drinking: 1 to $4:-0.42(-2.67)$

5. Female model: Sighted: Adj $R^{2}: 37.01 \%, F: 13.16(p=0.0000), n=270$.

Constant: $2.16(11.97)$

Blind Rating: 0.34 (5.83).

Brand: Cellar Cask: -0.66 (-4.25), Brand: Es La Vida: -0.60 (-3.95), Brand: Fourth Street: -0.31 (-2.07).

Subject control: subj. 51: 1.24 (3.39), subj. 31: 1.21 (3.32), subj. 26: -0.90 (-2.44), subj. 29: -0.87 (-2.40), subj. 68: -0.87 (-2.36), subj. 28: 0.85 (2.29), subj.

30: 0.79 (2.17). subj. 67: $-0.76(-2.07)$.

Behavioural control: Secondary Education: -0.45 (-3.73).

6. Wine Novice model: Sighted: Adj $R^{2}: 45.46 \%, F: 18.45(p=0.0000), n=336$.

Constant: 1.62 (13.40).

Blind Rating: 0.40 (8.84).

Brand: Es La Vida: -0.30 (-2.81), Brand: Four Cousins: 0.30 (2.77).

Subject control: subj. 4: 1.55 (5.19), subj. 27: -1.55 (-5.14), subj. 51: 0.90 (3.02), subj. 31: 0.90 (3.02), subj. 18: -0.85 (-2.83),

subj. 48: -0.85 (-2.81), subj. 33: $-0.83(-2.77)$, subj. 20: $-0.80(-2.67)$, subj. 82: $-0.70(-2.34)$, subj. 68: $-0.68(-2.26)$,

subj. 36: 0.70 (2.33), subj. 42: $-0.63(-2.10)$, subj. 67: $-0.60(-2.00)$.

7. Wine Intermediate model: Sighted: Adj $R^{2}: 38.25 \%, F: 25.93(p=0.0000), n=162$.

Constant: 1.24 (6.30).

Blind Rating: 0.54 (7.84).

Brand: Four Cousins: 0.48 (2.40).

Subject control: subj. 29: $-1.11(-2.76)$, subj. 26: $-0.99(-2.42)$.

8. Age: '18-21' model: Sighted: Adj $R^{2}: 34.99 \%, F: 19.89(p=0.0000), n=282$.

Constant: 1.66 (11.53).

Blind Rating: 0.43 (8.05).

Brand: Es La Vida: -0.57 (-4.20), Brand: Cellar Cask: -0.56 (-4.06).

9. Age: '22 or older' model: Sighted: Adj $R^{2}: 57.11 \%, F: 21.45(p=0.0000), n=216$.

Constant: $1.78(11.63)$.

Blind Rating: 0.40 (6.90).

Brand: Fourth Street: -0.41 (-3.03), Brand: Es La Vida: -0.40 (-2.94).

Subject control: subj. 4: 1.53 (5.04), subj. 27: -1.25 (-3.96), subj. 56: 0.90 (2.90), subj. $59: 0.87$ (2.73), subj. $29:-0.85$ (-2.71),

subj. 69: 0.82 (2.63), subj. 26: -0.84 (-2.61), subj. 32: 0.82 (2.61), subj. 36: 0.68 (2.21), subj. 6: 0.91 (2.84).

Behavioural control: Secondary Education: $-0.32(-2.55)$. 


\section{Results}

\section{The meta-model}

Drawn from Table 2, we present below key components of the equation modelling all sighted scores for each wine $(i)$, together with the relevant $t$ statistics.

$$
\begin{aligned}
& \text { Sighted score }_{\mathrm{i}}=1,77+0,37 \text { Blind rating }_{i}+0.25 \text { (Four Cousins) } \\
& \text { t score: } \quad(15,57) \quad(9,22) \quad(2,53) \\
& \text { - } 0.43 \text { (Es La Vida) - 0,37 (Cellar Cask })+19 \text { subject controls }+\varepsilon_{i} \\
& (-4,35) \\
& (-3,70)
\end{aligned}
$$

Observing the model constant we conclude that the sighted score is likely to be 1,77 stars holding all independent variables are at zero. The first variable is the blind rating where we note that for each blind or 'intrinsic' star, the sighted score is likely to increase by a fraction more than a1/3 of a star. Noting that the mean blind score is 2,35 stars, the variable effect of blind ratings is thus likely to contribute an average 0,88 stars to the equation as a whole; just over $1 / 3$ of the mean sighted rating of 2,51 .

With the statistically dominant 'blind' cue accounted for, the five candidate brand cues now become relevant. From the outset we note that only three of the five present as placebo type brands in the meta-model: Four Cousins (0,25 stars), Es La Vida (-0,43 stars) and Cellar Cask (-0,37 stars). Of these, the former, Four Cousins, is by far the strongest, contributing a positive quarter of a star to its sighted rating regardless of its intrinsic merit. This is 0,68 and 0,62 stars more than the Cellar Cask and Es La Vida brand-effects, respectively. (These two brands carry negative brand effects, not positive.) Put differently, the Four Cousins brand effect carries more than two-and-a-half times the strength of its next strongest rival. This said, the 0,25 Four Cousins brand effect constitutes less than a tenth of its 2,90 mean average sighted score.

There are no demographic control factors identified in the meta-model, although 19 of the 83 subjects are identified as carrying statistically significant levels of bias. These respondents are all notified in Table 2.

\section{The education models}

We also sought to establish how subjects with different educational backgrounds responded to the available brand cues. Two models (secondary and tertiary) were constructed for this purpose (see Table 2).

A ten-factor model was produced for those 46 subjects with secondary education. The blind rating is the first of these factors, with a coefficient of $0,43(t=6,88)$. Out of the eight sub-models this is the joint highest of the blind cue coefficients. Next, Four Cousins is identified as the only brand within this segment $(0,33$ stars, $t=2,33)$. This brand coefficient is 0,18 stars (or $72 \%$ ) stronger than its equivalent in the meta-model. Finally, eight subjects are identified as carrying statistically significant levels of bias. (See Table 2 for details.)
For those 37 subjects with tertiary education, a thirteenfactor model emerges, although this time with three brands, not one. Firstly, however, the blind rating presents with a coefficient of $0,37(t=6,88)$, somewhat weaker than the blind coefficient of the secondary education model $(0,43)$. Thereafter follow the three brands: Four Cousins (0,52 stars, $t=3,77)$, St Claire (0,34 stars, $t=2,44)$ and Es La Vida $(-0,34$ stars, $t=-2,53)$. Notably the Four Cousins brand, which features in six of the nine models, presents with its strongest coefficient here: its 0,52 coefficient being more than double the strength of its meta-model coefficient $(0,25, \mathrm{t}=2,53)$. Additionally, Table 2 identifies nine subjects presenting with significant levels of bias.

\section{The gender models}

Models for male and female subjects are found to differ in certain respects (see Table 2). Firstly, the male model $(n=38)$ is the strongest of all nine models developed, with an adjusted $\mathrm{R}^{2}$ figure of $61,5 \%$. The female model $(\mathrm{n}=45)$ is weaker with an adjusted $\mathrm{R}^{2}$ of only $37,0 \%$. Secondly, the male blind rating coefficient of $0,40(t=7,87)$ contrasts with the female model's weaker blind rating coefficient of 0,34 $(t=5,83)$. Thirdly, the composition of brands identified in each model is entirely different. In the female model three brands are noted: Cellar Cask (-0,66 stars, $t=-4,25)$, Es La Vida (-0,60 stars, $t=-3,95)$ and Fourth Street (-0,31 stars, $t=-$ $2,07)$. In the male model the remaining two brands are noted: Four Cousins (0,50 stars, $t=4,42)$, and St Claire $(0,51$ stars, $t=4,50)$. In contrast to the brand coefficients in the aforementioned female model, here both effects are positive. Moreover, since these two brands are found in neither the female nor any of the age-based models, we can assert that for young and old, Four Cousins and St Claire are clearly male brands, with obvious marketing implications that follow.

Both gender models present with demographic control factors. In the male model it is noted that the 34 subjects with up to four years of wine drinking experience are likely to deduct 0,42 stars from their scores, ceteris paribus. In the female model, those with no tertiary education $(n=28)$ will deduct 0,45 stars $(t=-3,73)$.

Finally, as per Table 2, subject controls indicate that 14 male and 13 female subjects present with statistically significant levels of bias.

\section{Wine expertise models}

Seeking also to determine how relative expertise impacted on the sighted assessment of wine, we generated models for those who considered themselves either (1) novices $(n=56)$, or (2) intermediates $(n=27)$. (Recall, no subjects identified themselves as experts). Models for each categorization appear in Table 2 .

In the sixteen factor novice model $(n=56)$, the blind-based coefficient of $0,40(t=13,40)$ is comparable with that of the male model. In the intermediate model however, this variable coefficient $(0,54, t=7,84)$, is substantially $(35 \%)$ higher and is the highest across all the nine models. The novice model then identifies two brand effects: Four 
Cousins (0,30 stars, $t=2,77)$ and Es La Vida (-0,30 stars, $t=-$ $2,81)$. Both are common to the meta-model. Finally 13 novice respondents are identified with statistically significant levels of bias.

The intermediate model presents with only four factors: the already noted blind rating, the seemingly ubiquitous Four Cousins (for which the comparatively high brand coefficient of 0,48 stars $(t=2,40))$ compares well with the coefficients in the male $(0,50)$ and tertiary education $(0,52)$ models), and two subject control-effects.

\section{Age models}

Finally we explored whether certain age categories responded differently to different brands. Two models were developed: an eight-factor model for those between 18 and 21 years $(n=47)$; and a 14-factor model for those between 22 and 30 years old $(n=36)$ (see again Table 2). The youthful character of the entire sample across these two categories is in line with the aim of the experiment: to test the youth market for brand effects stemming from entry-level rosé brands.

Blind effects were noted in both categories: presenting with coefficients of $0,43(t=8,05)$ and $0,40(t=6,90)$ for the 'young' 18-to-21 and 'older' 22-to-30 models, respectively. The difference between these two coefficients is but 0,03 , implying little variation in the ability to discern intrinsic quality between the two closely proximate age segments of this study. This finding is not unexpected.

Two brand effects also present in the 18-to-21 model: Es La Vida $(-0,57$ stars, $t=-4,20)$ and Cellar Cask $(-0,56$ stars, $t=-$ 4,06 ). Both also appear in the meta-model (with respective brand-effect-coefficients of $-0,43$ and $-0,37$ ), although in this instance with substantially greater negative brand effects.

For 'older' drinkers between 22 and 30, two brand effects are also noted: once more Es La Vida (although here with a less severe $-0,40$ stars, $t=-2,94)$, and Fourth Street $(-0,41$ stars, $t=-3,03)$. One demographic control factor is also featured in this 'older' model: those with only secondary education will deduct 0,32 stars $(t=-2,55)$.

Once more, the imposition of subject controls proves useful, revealing that across these two sub-models, 8 and 14 subjects present with respectively overt measures of bias.

Table 3 below provides a comparative summary of the various brand effects and factors of demographic and subject control as they present across all of the models in this study. Finally, in Figure I we present a graphical depiction of the scale of each of the notified brand effects featured in each model.

Table 3: Summation table. An overview of variables notified across the meta and demographic sub-models developed in this study.

\begin{tabular}{|c|c|c|c|c|c|c|c|c|c|c|c|c|}
\hline & & & & \multicolumn{2}{|c|}{ Education } & \multicolumn{2}{|c|}{ Gender } & \multicolumn{2}{|c|}{ Expertise } & \multicolumn{2}{|c|}{ Age } & \multirow[b]{2}{*}{ 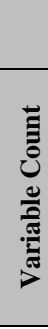 } \\
\hline & & & 离 & 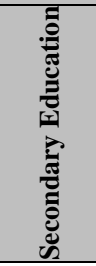 & 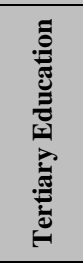 & $\frac{\tilde{\Xi}}{\Sigma \pi}$ & 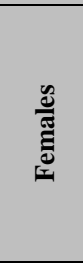 & $\begin{array}{l}\stackrel{0}{0} \\
z \\
z \\
z\end{array}$ & 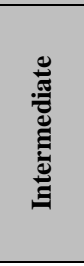 & 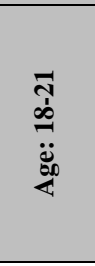 & 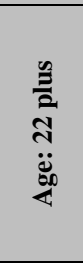 & \\
\hline \multirow{4}{*}{ 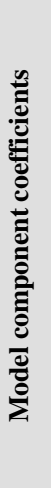 } & & Constant: & 1,77 & 1,40 & 1,66 & 1,78 & 2,16 & 1,62 & 1,24 & 1,66 & 1,78 & \\
\hline & & Blind factor: & 0.37 & 0,43 & 0,37 & 0,40 & 0,34 & 0,40 & 0,54 & 0,43 & 0,40 & 9 \\
\hline & छั & $\begin{array}{r}\text { Es La Vida: } \\
\text { Cellar Cask: } \\
\text { Fourth Street: } \\
\text { St Claire: } \\
\text { Four Cousins: }\end{array}$ & $\begin{array}{l}-0,43 \\
-0,37\end{array}$ & 0,33 & $\begin{array}{l}-0,34 \\
0,34 \\
0,52 \\
\end{array}$ & $\begin{array}{l}0,51 \\
0,50\end{array}$ & $\begin{array}{l}-0,60 \\
-0,66 \\
-0,31\end{array}$ & $-0,30$ & 0,48 & $\begin{array}{l}-0,57 \\
-0,56\end{array}$ & $\begin{array}{l}-0,40 \\
-0,41\end{array}$ & $\begin{array}{l}6 \\
3 \\
2 \\
2 \\
6\end{array}$ \\
\hline & 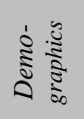 & $\begin{array}{r}\text { Secondary Education: } \\
\text { Yrs drinking }<5\end{array}$ & & & & $-0,42$ & $-0,45$ & & & & $-0,32$ & $\begin{array}{l}2 \\
1\end{array}$ \\
\hline \multirow{7}{*}{ 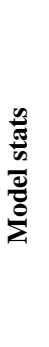 } & & Adjusted $R^{2}$ & $46,4 \%$ & $36,2 \%$ & $52,7 \%$ & $61,5 \%$ & $37,0 \%$ & $45,5 \%$ & $38,2 \%$ & $35,0 \%$ & $57,1 \%$ & \\
\hline & & F score & 19,7 & 16,6 & 19,9 & 26,9 & 13,2 & 18,4 & 38,2 & 19,9 & 21,45 & \\
\hline & & Subjects per model & 83 & 46 & 37 & 38 & 45 & 56 & 27 & 47 & 36 & \\
\hline & \multirow{4}{*}{ 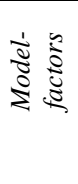 } & Brand & 3 & 1 & 3 & 2 & 3 & 2 & 1 & 2 & 2 & \\
\hline & & Subject & 19 & 8 & 9 & 10 & 8 & 13 & 2 & 5 & 10 & \\
\hline & & Demographic & 0 & 0 & 0 & 1 & 1 & 0 & 0 & 0 & 1 & \\
\hline & & Total factors per model & 23 & 10 & 13 & 14 & 13 & 16 & 4 & 8 & 14 & \\
\hline
\end{tabular}




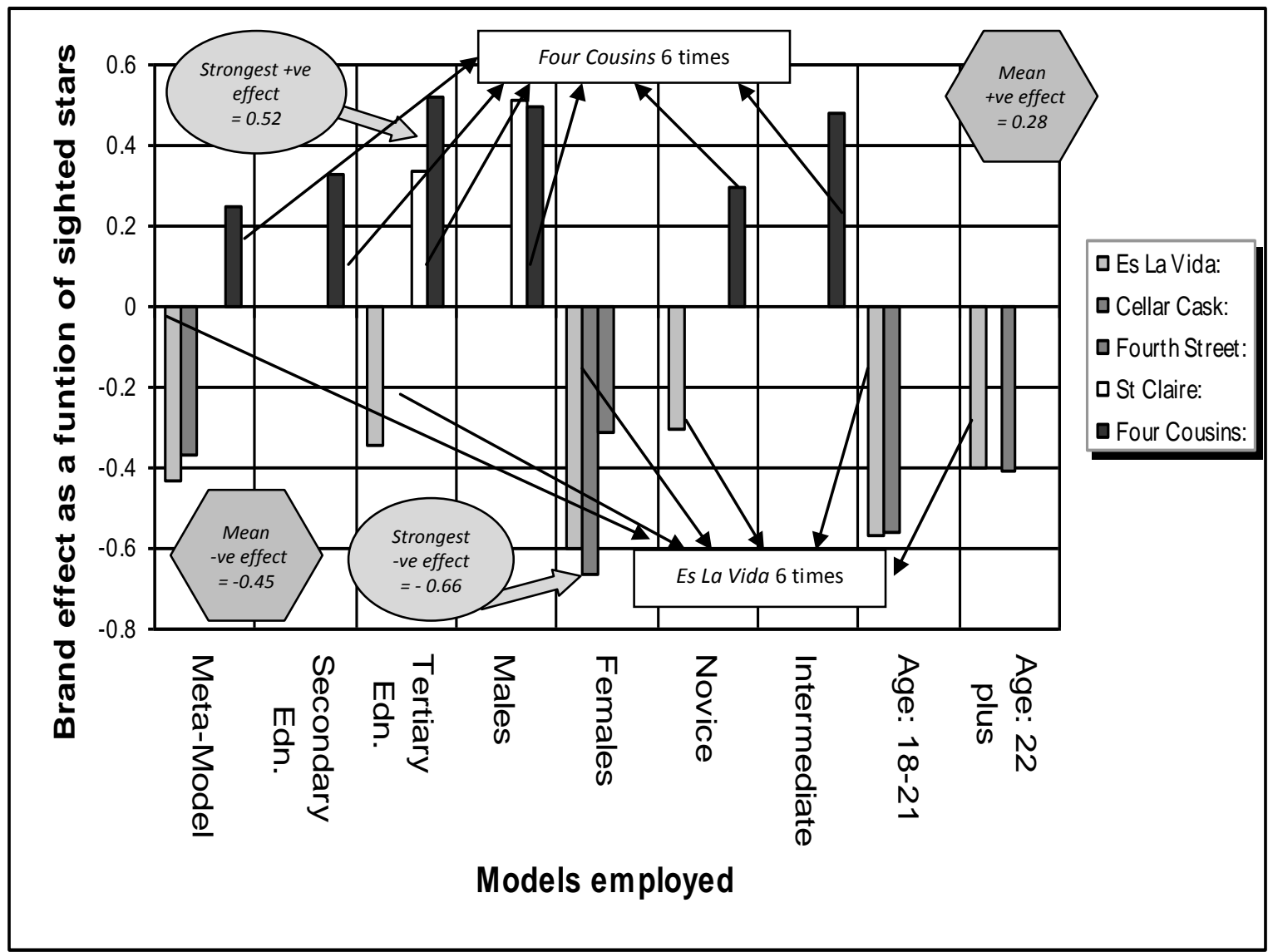

Figure I: Notified brands and their effect sizes per model. Observe how Four Cousins appears in six of the models - with brand effects of varying sizes although all positive. Es La Vida also appears six times, although by comparison, on all occasions the effect is negative. The remaining three brands appear fleetingly, with St Claire presenting with positive effects; Cellar Cask and Fourth Street with negative effects.

\section{Conclusion}

This study sought to demonstrate how placebo-styled brand effects might be observed and measured across certain demographic user-profiles. Through the statistical treatment of blind and sighted ratings drawn from a sample of 83 youthful wine tasters, a set of regression models was thus developed to observe the extent to which certain brand cues mediate the sighted appreciation of a wine when controlling for earlier blind-based scores. The experiment was so constructed that only one sighted cue (the brand) was provided and thus no additional cue controls were required.

Across all nine models, the presence and strength of five candidate brands was tested relative to a pre-identified brand dummy comparator, Robertson Winery. Relatively, brand effects were thus noted to be either positive or negative. The average positive brand effect was 0,28 sighted stars, roughly $1 / 10^{\text {th }}$ of the sighted mean $(2,97)$. The average negative brand effect was $-0,45$; more than $1 / 6^{\text {th }}$ of the sighted mean. These effects are not insignificant, suggesting that the brand cue can have a marked impact on the sighted appreciation of wine. Additionally, no more than three of the five brands were notified in any given model; confirming that some brands create more presence in the mind than do others.
Moreover, across the various user-profiles some brands presented more consistently than others. For example Es La Vida and Four Cousins featured six times; Fourth Street and St Claire only twice.

Cross sector comparisons revealed that those with tertiary education appeared to employ more brands than those with only secondary levels of education (by a margin of 3 to 1 ). Similar dynamics were observed across the two gender models: the sighted ratings of women being impacted by three of the five brands, and those of men by the remaining two.

Two men's brands were clearly identified in Four Cousins and St Claire; since both featured in neither the age-based models, nor in the female model, yet emerged the strongest of all the brand effects notified across the sample, with cue effects of half a star each. The identification of such brands confirms the efficacy of this method in affordably (and rapidly) identifying potentially important segment-specific brands. For management this is clearly important. The dissection of generic target markets to reveal more tightly defined user-segments is clearly cost and strategy effective. 
Our findings also raise the question why male and female subjects appear to respond as differently to brands as they did in this study. Gender, of all user profiles under analysis in this study, showed the greatest variation in brand selection and affectation. This said, quite why we observe such variation across gender transects is not clearly understood and further study on the nature and rate of cueconditioning is anticipated. When, for example, do gender differences in cue-response begin to manifest. What other factors might determine this trend, and how do gender variations connect with 'general' neurological systems which strive to produce both deliberate and intuitive systems of thought?

Recent pieces by Ross (2010), Schroeder (2010) and Kahneman (2012) all propose that, in the interpretation of external cues, the more deliberate and strategic executive system of the brain (so-called "system 2") is literally mugged by the more impulsive and intuitive neurological "system 1"; understood to be based in areas like the amygdala and ventral striatum. In the task of invoking extrinsic brand-like cues to make rapid sense of complicated information dynamics, short-term irrational "system 1" behaviour is thus likely to countermand any sense of "system 2's" style of slower logical analysis and judgement. In wine terms, this dual-system dynamic could be analysed by either increasing or reducing the response time of sighted tastings, relative to blind. Thus, for example, by extending periods of sighted deliberation, consequent sight-based wine assessments might show higher correlations with blind assessments. Conversely by reducing the sight-based response period to no more than a few seconds, one might anticipate a lower correlation.

Run across demographic transects (like gender and experience), comparative time treatments of this nature would help shed light on the issues outlined above.

\section{References}

Allison, R.I. \& Uhl, K.P. 1964. 'Brand identification and perception', Journal of Marketing Research, 1: 80-85.

Almenberg, J. \& Dreber, A. 2011. 'When does the price affect the taste? Results from a wine experiment,' Journal of Wine Economics, 6(1): 110-121.

Ariely, D. \& Norton M.I. 2009. 'Conceptual consumption', Annual Review of Psychology, 60: 475-499.

Borsook, D. \& Becerra, L. 2005. 'Placebo: From pain and analgesia to preferences and products', Journal of Marketing Research, 42 (November): 394-398.

Erdem, T. \& Swait, J. 1998. 'Brand equity as a signaling phenomenon', Journal of Consumer Psychology,7(2): 131157.

Halstead, L. 2002. 'How do customers select wine? Factors that affect the purchase decision making process in the wine category', Research proceedings: Annual Academy of Marketing.
Kahneman, D. 2012. Thinking, fast and slow. London: Penguin Books.

Kamakura, W.A. \& Russell, G.J. 1993. 'Measuring brand value with scanner data', International Journal of Research Marketing, 10: 9-21.

Keller, K.L. 1993. 'Conceptualizing, measuring and managing customer-based brand equity', Journal of Marketing, 57: 1-22.

Malhotra, N.K. 2010. Marketing research: An applied orientation. $6^{\text {th }}$ Edition. Upper Saddle River, New Jersey: Pearson Education International.

Moerman, D.E. \& Jonas, W.B. 2002. 'Deconstructing the placebo effect and finding the meaning response', Annals of Internal Medicine, 136(6): 471-476.

Montague, R. 2006. Why choose this book? How we make decisions. New York: Dutton Press.

Mueller, S., Osidacz, P., Francis, I.L. \& Lockshin, L. 2010. 'The relative importance of extrinsic and intrinsic wine attributes: Combining discrete choice and informed sensory consumer testing'. Paper read at the 5th International Academy of Wine Business Research Conference 8-10 Feb 2010, Auckland (NZ).

Plassmann, H., O’Doherty, J., Shiv, B. \& Rangel, A. 2008. 'Marketing actions can modulate neural representations of experienced pleasantness', Proceedings of the National Academy of Sciences, 105(3): 1050-1054.

Priilaid, D, Sevenoaks M, Aitken, R, \& Chisholm, C. (2013). 'How price cues impair objective product assessment across age and experience strata', International Journal of Wine Business Research,25(2): Pre-published online see:

http://www.emeraldinsight.com/journals.htm?issn=1751-1062

Priilaid, D. 2006. 'Wine's placebo effect: How the extrinsic cues of visual assessment mask the intrinsic quality of South African red wine', International Journal of Wine Marketing, 18(1): 17-32.

Priilaid, D. 2007. 'The placebo of place: Terroir effects in the blind and sighted quality assessments of South African varietal wines', Journal of Wine Research, 18(2): 87-105.

Priilaid, D. \& Van Rensburg, P. 2010. 'Symbolic and functional brand effects in the hedonic assessment of South African wines', South African Journal of Business Management, 41(3): 47-69.

Priilaid, D., Feinberg, J., Carter, O. \& Ross, G. 2009. 'Follow the leader: How expert ratings mediate consumer assessments of hedonic quality', South African Journal of Business Management, 40(4): 15-22.

Ross, D. 2010. 'Economic models of pathological gambling.' In Ross, D., Kinkaid, H., Spurrett, D. \& Collins, 
P. What is addiction? Cambridge, MA: The MIT Press, pp. 131-158.

Schroeder, T. 2010. 'Irrational action and addiction.' In Ross, D., Kinkaid, H., Spurrett, D. \& Collins, P. What is addiction? Cambridge, MA: The MIT Press, pp.391-408.

Siegrist, M. \& Cousin, M. 2009. 'Expectations influence sensory experience in a wine tasting', Appetite, 52: 762-765.

Spawton, T. 1991. 'Marketing and planning for the wine industry', European Journal of Marketing, 24(3): 6-48.

Thrane, C. 2004. 'In defence of the price hedonic model in wine research', Journal of Wine Research, 15: 123-134. 
